\title{
Improvement of the chemical, thermal, mechanical and morphological properties of polyethylene terephthalate-graphene particle composites
}

\author{
SAMEER A AWAD* and EMAN M KHALAF \\ Department of Chemistry, College of Education for Pure Science, University of Al-Anbar, Ramadi 31001, Iraq \\ *Author for correspondence (sameer.msc1981@gmail.com)
}

MS received 7 June 2017; accepted 23 September 2017; published online 16 May 2018

\begin{abstract}
The graphene powder was used as a reinforcement in polyethylene terephthalate (PET) with various weight percentages $0.1,0.5,1$ and $2 \mathrm{wt} \%$. To prepare PET/graphene powder composites, melt-mixing process was followed. The crosslinking degree between PET and functionalized graphene increased, which was indicated by carbonyl indexes (Fourier transform infrared spectra) when interfaced with PET. The results of thermal properties showed that adding $2 \mathrm{wt} \%$ of graphene composites improved the thermal stability, transition glass temperature $T_{\mathrm{g}}$, crystallinity temperature point and chemical properties of PET. The results of thermal gravimetric analysis showed that the highest addition of graphene ( $2 \mathrm{wt} \%$ ) into the PET slightly improves both the residue yields and thermal stability. The tensile strength of PET was highly increased with the increased loading of graphene, and the elongation was reduced, compared with PET without filler. The results of X-ray diffraction curves showed that $2 \%$ incorporation of graphene into PET has good interfacial interaction and higher intensity. The scanning electron microscopy micrographs showed a high compatibility between the pure PET and graphene composite chains.
\end{abstract}

Keywords. Polyethylene terephthalate; graphene composite; thermal stability; crystallinity; tensile strength.

\section{Introduction}

Polymer nanocomposites are one of the important class of composite materials [1]. Polyethylene terephthalate (PET) is used in many industrial products, such as PET soft drink water bottles, because of high resistance and chemically it does not have contact with the liquid, so it is not toxic [2-4]. Recently, many composites such as graphene are applied in the synthesis of PET nanocomposites via polymerization and a mixing technique [5]. PET is a stable material while it absorbs very little water [6]. Although PET is widely used in the fibres and packaging industries, which require thermal stability and thermal conductivity, it has limitation due its poor thermal stability and conductivity. Such areas include but not limited to heat dissipation in electrical/electronic components [7].

Graphene is a significant nanocarbon multifunctional material and has become the topic of research interest around the world according to the structure and mechanical and electronic properties [8-10]. Graphene composites have excellent electronic, thermal, and mechanical properties and create dimensional material for functional materials. They display novel properties when they combine with polymers as composites [11,12]. The incorporation of graphene in polymers as composites such as PET has importance in industrial applications attributable to improve mechanical, chemical and thermal properties [13].

\section{Experimental}

\subsection{Materials}

In this study, PET as granular form, density $1.68 \mathrm{~g} \mathrm{ml}^{-1}$ at $25^{\circ} \mathrm{C}$, was supplied from Sigma-Aldrich Company, UK. Graphene composite powder (purity $99.6 \%$, particle size $20 \mu \mathrm{m}$, density $0.12 \mathrm{~g} \mathrm{~cm}^{-3}$ ) was provided by Graphene Lab Ltd.

\subsection{Preparation of carboxylic groups functionalized graphene composite powder}

Graphene composite powder $(10 \mathrm{~g})$ was dissolved in the mixture of $150 \mathrm{ml}$ nitric acid $(65 \%)$ and $50 \mathrm{ml}(3: 1 \%)$ sulphuric acid in a round bottom flask equipped with a condenser and refluxed for about $16 \mathrm{~h}$ to create carboxyl functional groups on graphene structure. The functionalized graphene solutions were filtered and then washed with deionized water to attain the value of $\mathrm{pH}=7$. After the filtration, graphene was dried at $65^{\circ} \mathrm{C}$ in a vacuum oven for $24 \mathrm{~h}$. Figure 1 shows a suggested synthesized equation of functionalized graphene nanoparticle. 


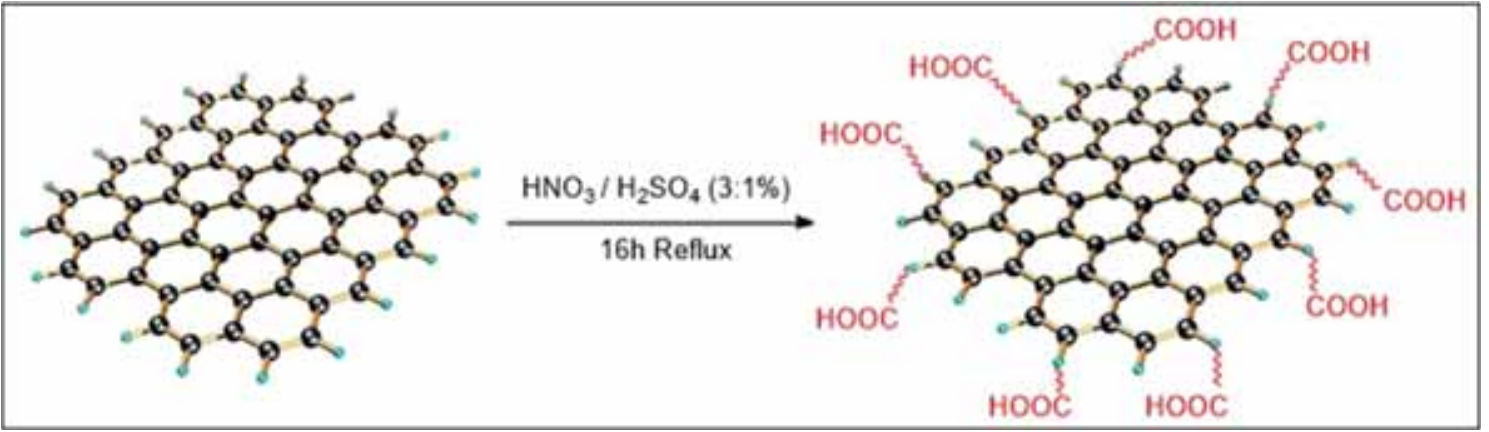

Figure 1. Equation of functionalized graphene nanoparticle.

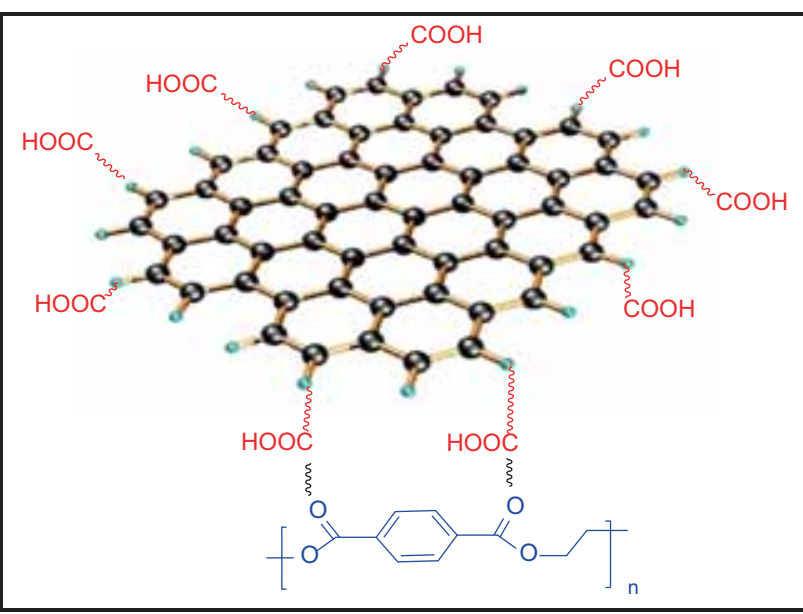

Figure 2. Schematic showing possible interactions between the carboxylic groups functionalized graphene fillers and the PET matrix.

\subsection{Synthesis of PET-graphene composites}

Various weights $(0.1,0.5,1$ and $2 \mathrm{wt} \%)$ from functionalized graphene with PET were prepared by Mixing technique. This method was performed in two steps: in the first step, the PET and graphene composite powder were placed inside a chamber and mixed for $20 \mathrm{~min}$ at $40 \mathrm{rpm}$. Later the mixing speed was increased to $80 \mathrm{rpm}$ for $15 \mathrm{~min}$ more. The PET-graphene composite mixture was then laminated by compression of aluminium molding into thin sheets of $80 \times 80 \times 5 \mathrm{~mm}$ and then left in a vacuum oven at $170^{\circ} \mathrm{C}$ annealing to remove any bubbles from samples. Figure 2 illustrates the schematic interaction between pure PET and functionalized graphene composites.

\subsection{Fourier transform infrared tests}

The tests of PET nanocomposite specimens were carried out by Perkin-Elmer Fourier transform infrared (FTIR) spectrophotometer with wavelength range $4000-500 \mathrm{~cm}^{-1}$ to indicate and label the changes in the absorbance intensities of the carbonyl group $\left(1710 \mathrm{~cm}^{-1}\right)$ of pure PET and PETgraphene composites. The carbonyl index-the ratio was measured based on the absorbance of both carbonyl groups and an unalterable band $\left(1508 \mathrm{~cm}^{-1}\right.$, aromatic ring $\mathrm{C}=\mathrm{C}$ bond).

$$
\begin{aligned}
& \text { Carbonyl index }\left(I_{\mathrm{CO}}\right)=\mathrm{Abs} \\
& \text { at } 1710 \mathrm{~cm}^{-1} / \mathrm{Abs} \text { at } 1508 \mathrm{~cm}^{-1}
\end{aligned}
$$

\subsection{Thermalgravimetric tests}

Thermogravimetric instrument (Perkin-Elmer Company) was used to analyse the thermal degradation of pure PET nanocomposite specimens. The heating rate of samples was $10^{\circ} \mathrm{C} \mathrm{min}^{-1}$ in the range $20-600^{\circ} \mathrm{C}$, and the weight of the sample was in the range between 5 and $10 \mathrm{mg}$. The loss of mass was followed in response to increase in the temperature of both pure PET and PET-graphene composite.

\subsection{Differential scanning calorimetry}

The differential scanning calorimetry (DSC) tests were carried out using a Perkin-Elmer thermal analysis. The heating rate of all samples was $10^{\circ} \mathrm{C} \mathrm{min}{ }^{-1}$ within temperature range $50-600^{\circ} \mathrm{C}$. The fusion enthalpy $\left(\Delta H_{\mathrm{f}}\right)$ of PET was measured, and the degree of crystallinity, $X_{\mathrm{c}}(\mathrm{PET})$, was calculated using the following equation:

$$
\% X_{\mathrm{c}}(\mathrm{PET})=\frac{\Delta H_{\mathrm{f}}(\mathrm{PET})}{\Delta H_{\mathrm{f}}^{\circ}(\mathrm{PET})} \times \frac{1}{W(\mathrm{PET})} \times 100
$$

$\Delta H_{\mathrm{f}}^{\circ}=140 \mathrm{~J} \mathrm{~g}^{-1}$ and $W(\mathrm{PET})$ is the weight fraction of PET [14].

\subsection{Tensile strength tests}

Tensile strength was studied by using a Universal Instron testing machine (Model 5567). The specimens were tested according to ASTM D638 using dumbbell specimens with 


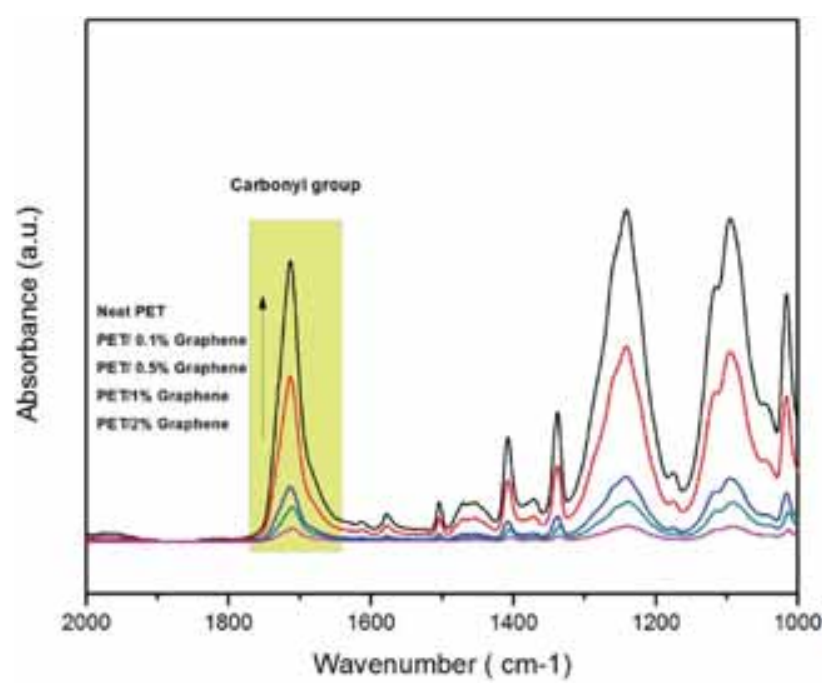

Figure 3. FTIR absorbance spectra of carbonyl groups of pure PET and PET-graphene composites.

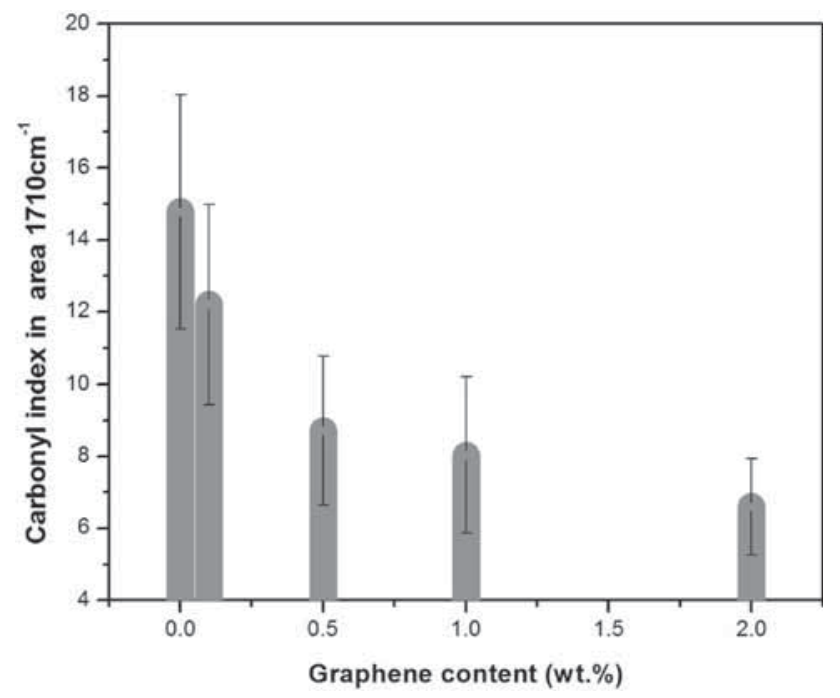

Figure 4. Carbonyl index of PET and PET-graphene composites.

dimensions $100 \mathrm{~mm}$ length, $10 \mathrm{~mm}$ width and $2 \mathrm{~mm}$ thickness. The testing speed was $5 \mathrm{~mm} \mathrm{~min}^{-1}$. Specimens were kept vertically between the grips for each test. Three specimens were tested for each test.

\section{$2.8 \quad X$-ray diffraction}

X-ray diffraction (XRD) measurement was performed using a Shimadzu XRD 6000 X-ray diffractometer type Shimadzu (Japan) with $\mathrm{CuK} \alpha$ radiation $(\lambda=1.542 \AA$ ) operated at an accelerating voltage of $40 \mathrm{kV}$ and the current of $40 \mathrm{~mA}$. Data were recorded at the scan rate of $2^{\circ} \mathrm{min}^{-1}$.

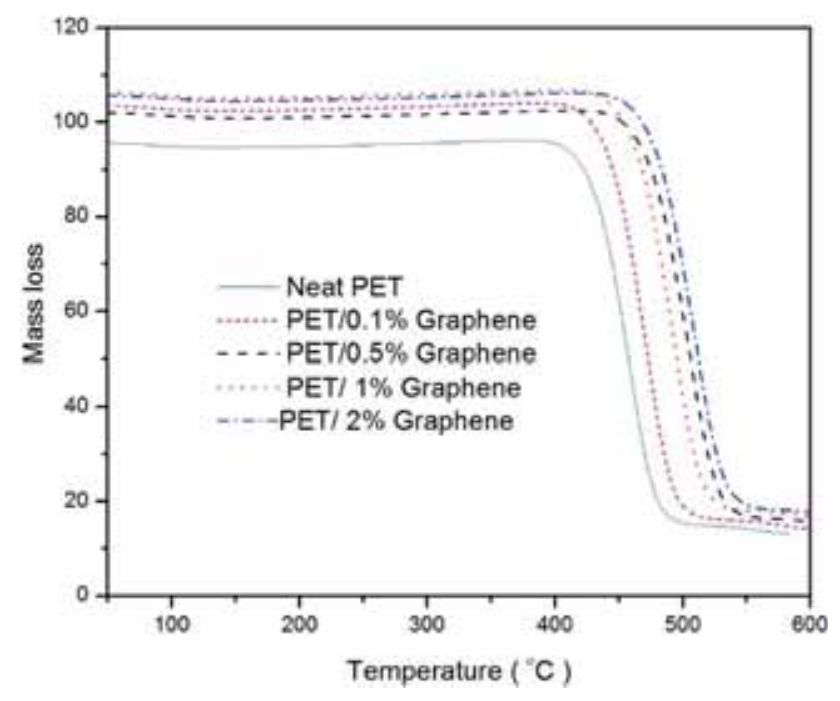

Figure 5. TGA thermogram curves of PET and PET-graphene composites.

\subsection{Scanning electron microscopy}

A JEOL JSM-5510 SEM (scanning electron microscopy; JEOL Pty Ltd, USA) was used, and composite specimens were prepared by gold coating. The surface of composites was investigated to follow the effects of graphene contents on pure PET.

\section{Results and discussion}

\subsection{FTIR spectroscopy analysis of PET nanocomposites}

The data obtained from FTIR spectra of the PET and PETgraphene composites can help determine the percent of carbonyl group indexes, which are related to crosslinking density between pure PET and graphene composites, as shown in figure 3, within the range $700-4000 \mathrm{~cm}^{-1}$. Figure 4 explains comparison of the carbonyl index of pure PET and PET with different ratios of graphene. The increase in incorporation of graphene between 0.1 and wt $\%$ attributed to decrease the intensity of absorbance of the carbonyl group of pure PET in the region $1710 \mathrm{~cm}^{-1}$, as shown in figure 4 . The obtained results indicated that carboxylic groups were more interactive on the pure PET surface. The $\mathrm{COOH}$-graphene was efficiently induced via chemical modification. This shows that the dispersion of the $\mathrm{COOH}$-graphene composite in the pure PET matrix will be more efficient than PET pure. Thus, it is projected that the functional groups efficiently induced on the surface of the graphene via chemical modification and enhanced the interactions between PET molecules.

\subsection{Thermal degradation of PET nanocomposite specimens}

Thermal degradation performance of the pure PET and graphene samples is shown in figure 5 , and $T_{\text {onset }}$ states to 
Table 1. TGA thermograms degradation and analysis results of PET and PET-graphene composites.

\begin{tabular}{lcccc}
\hline Samples $(\%)$ & $T_{\text {onset }}\left( \pm 0.1^{\circ} \mathrm{C}\right)$ & $T_{50}\left( \pm 0.1^{\circ} \mathrm{C}\right)$ & $T_{\max }\left( \pm 0.1^{\circ} \mathrm{C}\right)$ & Residual yield (\%) \\
\hline Pure PET & 117 & 243.5 & 490.5 & 17 \\
0.1 Graphene & 120.5 & 250.5 & 530.7 & 20 \\
0.5 Graphene & 122 & 255.3 & 540.8 & 22.5 \\
1 Graphene & 130 & 267.5 & 549.5 & 26.7 \\
2 Graphene & 168.5 & 289.6 & 598.6 & 28.5 \\
\hline
\end{tabular}

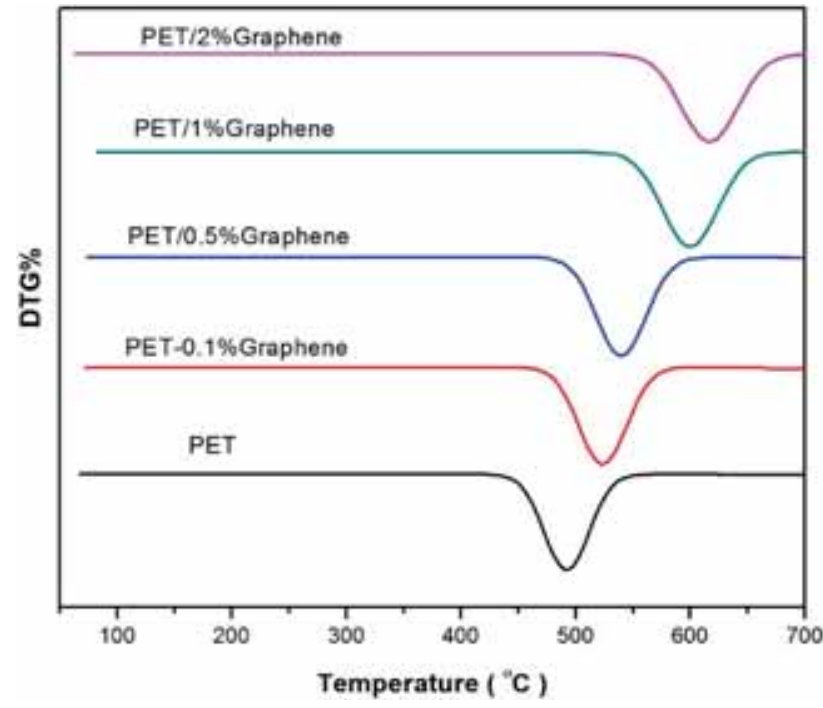

Figure 6. DTG thermogram curves of PET and PET-graphene composites.

the initial degradation temperature and is relevant factors indicating on the thermal stability. The maximum degradation temperature $\left(T_{\max }\right), T_{\text {onset }}$ and residual yield $\%$ at $600^{\circ} \mathrm{C}$ are summarized in table 1 . The shapes of the curves for the pure PET sample are the same as PET-graphene composite samples. From figures 5 and 6 , it can be observed that the thermal decomposition of samples decreased with the increase of the graphene contents from 0.1 to $2 \%$. The presence of the graphene composite leads to more stability of the PET matrix and gives good interfacial adhesion between the graphene composite and the pure PET. Table 1 shows that $T_{\text {onset }}, T_{50}$ and $T_{\max }$ residual yield and crystallinity temperature point $T_{\mathrm{c}}$ increased with the increase in the concentration of graphene ratios. The rise in the thermal stability of the PET nanocomposites was higher compared with pure PET. From table $1, T_{\max }$ of pure PET was $490.5^{\circ} \mathrm{C}$, while $T_{\max }$ of PET$2 \%$ graphene composite was about $598.6^{\circ} \mathrm{C}$. Residual yield was highest for PET-2\%graphene composite (28.5), while the pure PET shows $17 \%$, as shown in table 1 . These values in table 1 proved that graphene composites were accelerated by the effect of high protection against the thermal decomposition and enhanced the thermal stability of pure PET.

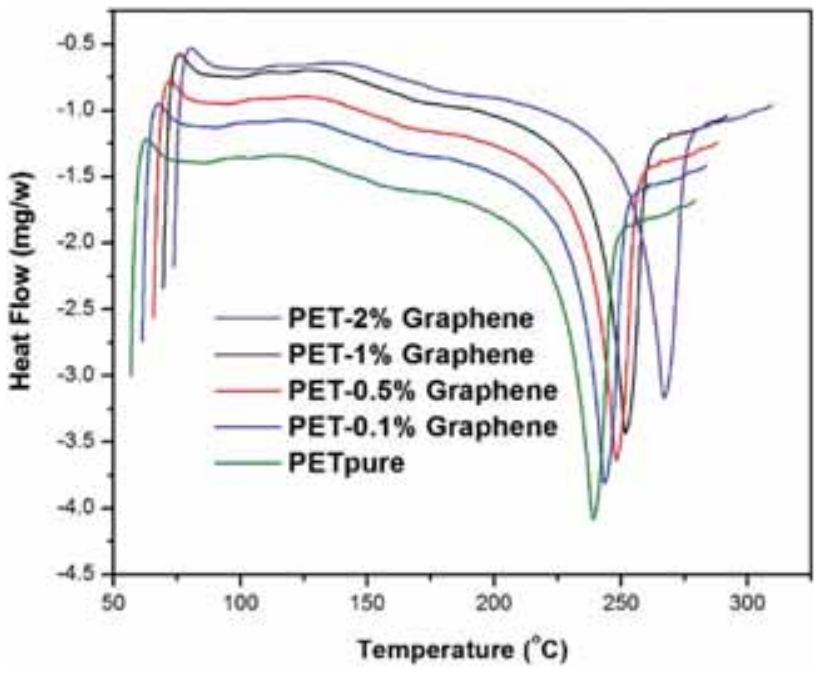

Figure 7. DSC curves of PET and PET-graphene composites.

Table 2. DSC thermograms degradation and analysis results of PET and PET-graphene composites.

\begin{tabular}{lcccc}
\hline Samples $(\%)$ & $T_{\mathrm{g}}\left({ }^{\circ} \mathrm{C}\right)$ & $T_{\mathrm{c}}\left({ }^{\circ} \mathrm{C}\right)$ & $\Delta H_{\mathrm{c}}\left(\mathrm{J} \mathrm{g}^{-1}\right)$ & Crystallinity $(\%)$ \\
\hline Pure PET & 117 & 235.5 & 26.44 & 17.52 \\
0.1 Graphene & 120.5 & 248 & 28.76 & 18.95 \\
0.5 Graphene & 122 & 252.5 & 30.45 & 22.43 \\
1 Graphene & 130 & 265.7 & 32.8 & 27.85 \\
2 Graphene & 138 & 274.6 & 37.2 & 30.55 \\
\hline
\end{tabular}

These indicate that the degree of crosslinking of graphene composites is more than that of bond break of pure PET. In the final stage of thermal, the mass loss of PET-graphene composite is less than the weight loss of pure PET [15]. From DSC tests that are presented in figure 7 and table 2, they showed that $2 \%$ graphene composite with pure PET exhibited higher temperature crystallinity point $\left(T_{\mathrm{c}}=274.6\right)$, compared with the crystallinity point (235.5) for pure PET. From the results that were obtained by DSC analysis (in table 2), the degrees of crystallinity improved and increased with the incorporation of graphene composite from 0.1 to $2 \%$ and the dramatic improvement was in $2 \%$ graphene composite $(30.55 \%)$ that was attributed to the homogeneous dispersion of the pure 


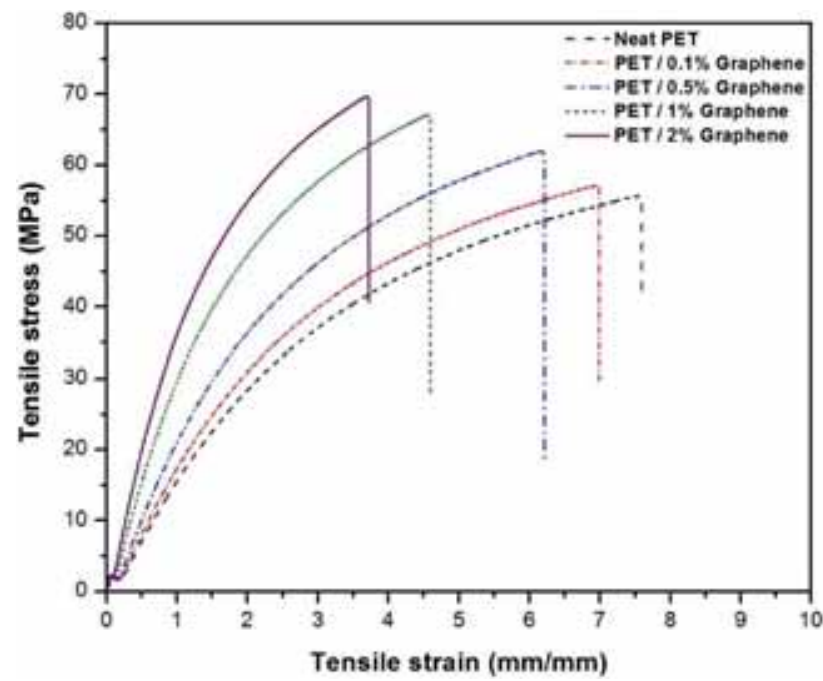

Figure 8. Tensile stress-strain curves of PET and PET-graphene composites.

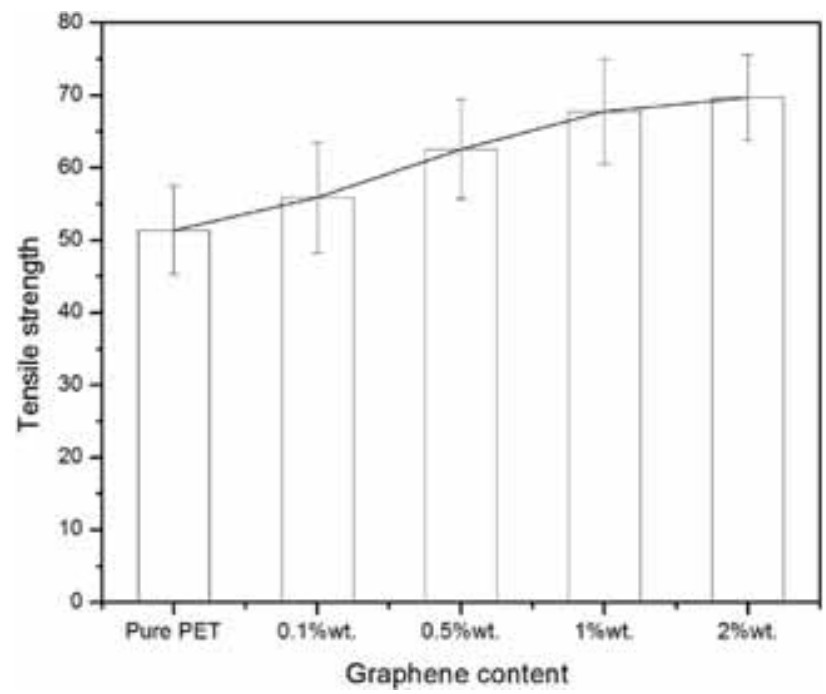

Figure 9. Tensile strength of PET and PET-graphene composites.

PET and graphene composite. Table 2 shows the relation between the glass transition temperature $T_{\mathrm{g}}$ and the amounts of graphene composites that were identified by DSC curves of figure 7 . The highest number from $2 \%$ graphene composite exhibited a higher value of $T_{\mathrm{g}}$ about $138^{\circ} \mathrm{C}$, compared with pure PET that was about $117^{\circ} \mathrm{C}$.

\subsection{Mechanical properties of nanocomposites}

To further analyse the influence of graphene addition to the mechanical properties of the PET composite, the following variables were assessed, both independently and regarding their mutual interaction: structure, oxidative treatment, and concentration level.

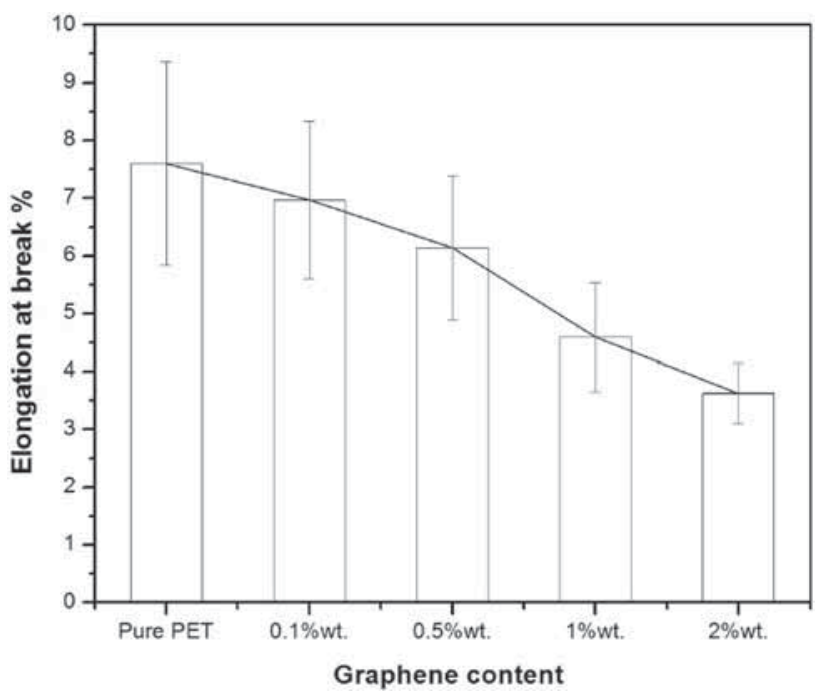

Figure 10. Elongation at break (\%) of PET and PET-graphene composites.

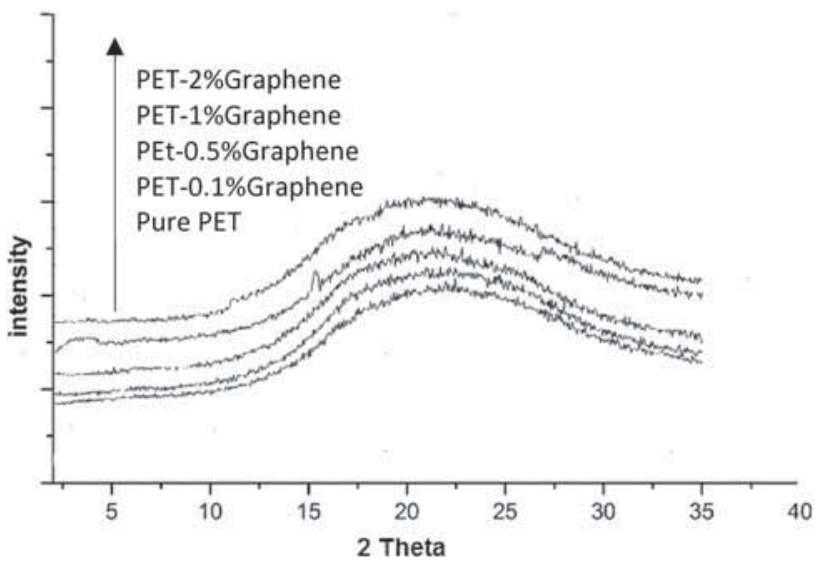

Figure 11. XRD patterns of PET and PET-graphene.

The results of the tensile tests showed that adding graphene particles increased the tensile strength and elongation [16]. The fracture strain decreased with addition of graphene. Figure 8 demonstrates the comparison of the tensile stress vs. strain for pure PET and PET nanocomposites. The addition of graphene to the PET composite induced a rise in tensile strength from 57, 62.5 to 69.4 and $70.5 \mathrm{MPa}$ for $0.1,0.5,1$ and $2 \mathrm{wt} \%$, respectively (figure 9), while pure PET exhibited the lowest value $54.5 \mathrm{MPa}$ of tensile strength. As in the case of the elongation at break was decreased from $7.5 \%$ for pure PET to $7.1,6.35,5.4$ and $3.2 \%$ for graphene content for $0.1,0.5,1$ and $2 \mathrm{wt} \%$, respectively (figure 10). While the surface functionality and dispersion of the material is initially inadequate, and the optimum addition of graphene ( $2 \mathrm{wt} \%)$ improved the mechanical properties of the PET nanocomposite. The interfacial adhesion also improved due to the compatibility between graphene and the PET matrix. 

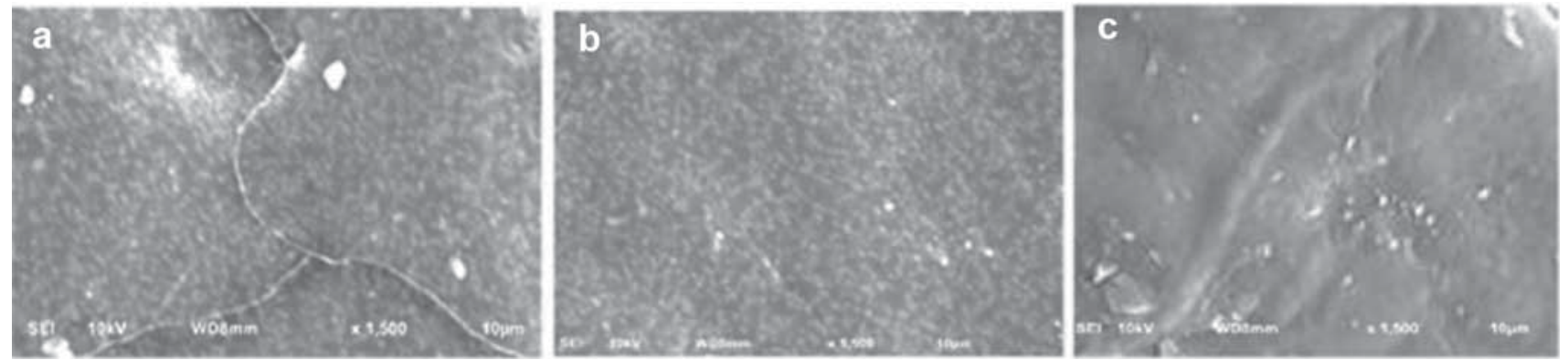

Figure 12. SEM micrographs comparison of (a) pure PET, (b) PET-0.1 graphene composite and (c) PET-2\% graphene composite.

\subsection{XRD analysis of PET and PET-graphene composites}

The results for the XRD patterns of neat PET and PET nanocomposites are shown in figure 8 . The PET and PETgraphene composites exhibit broad diffraction peaks, see figure 11 . The results of XRD proved that graphene contents are successfully incorporated into the PET matrix with higher diffraction (intensity), compared to PET without graphene contents.

\subsection{Morphology studies of PET nanocomposites through SEM}

The SEM observations reflect the results before and after adding graphene fillers. It is evident that more voids are present between molecules and chains of PET, as shown in figure 12a. After adding graphene composites for different concentrations provided higher crosslinking and better interface between the PET and graphene chains (2\% graphene), as shown in figure $12 \mathrm{c}$.

\section{Conclusion}

The increase in graphene composite content of $0.1-2 \mathrm{wt} \%$ enhanced the decrease in the intensities of absorbance in carbonyl region $\left(1710 \mathrm{~cm}^{-1}\right)$, compared to the intensity of absorbance of pure PET that increased in the same region. The highest content of graphene composites in pure PET exhibited more thermal stability and enhanced the increase in the degree of crystallinity as result of the high crosslink density with pure PET. The thermodynamic transition temperature $T_{\mathrm{g}}$ showed higher value after adding $2 \mathrm{wt} \%$ graphene composite. The tensile strength improved after adding $2 \mathrm{wt} \%$ graphene. Elongation decreased after addition of graphene content to pure PET. The XRD curves showed the strongest interaction with the highest amount of (1 and $2 \mathrm{wt} \%$ ) graphene. The SEM micrographs explained the highest homogenous dispersion between pure PET and $2 \mathrm{wt} \%$ graphene composites.

\section{Acknowledgements}

I would like to acknowledge The University of Al-Anbar-Iraq, Al-Anbar Technical Institute, and the University of Technology, Iraq, for the support and help to my research work.

\section{References}

[1] Abdul Razak N, Inuwa I, Hassan A S and Samsudin S 2013 Compos. Interfaces 20507

[2] Ávila Córdoba L, Martínez-Barrera G, Barrera Díaz C, Ureña Nuñez F and Loza Yañez A 2013 Int. J. Polym. Sci. 2013 Article ID 763276

[3] Koysuren O, Yesil S and Bayram G $2010 \mathrm{~J}$. Appl. Polym. Sci. 1183041

[4] Lim S and Chow W 2012 J. Appl. Polym. Sci. 1233173

[5] Liu W, Tian X, Cui P, Li Y, Zheng K and Yang Y 2004 J. Appl. Polym. Sci. 911229

[6] Moniruzzaman M and Winey K I 2006 Macromolecules 39 5194

[7] Chen H, Li Y, Zhang F, Zhang G and Fan X 2011 J. Mater. Chem. B 2117658

[8] Chen Z 2013 The crystallization of poly (ethylene terephthalate) studied by thermal analysis and FTIR spectroscopy (Doctoral dissertation, University of Birmingham)

[9] Dideykin A, Aleksenskiy A, Kirilenko D, Brunkov P, Goncharov V, Baidakova M et al 2011 Diamond Relat. Mater. 20 105

[10] Hu K, Kulkarni D D, Choi I and Tsukruk V V 2014 Prog. Polym. Sci. 391934

[11] Huang L, Zhan R and Lu Y 2006 J. Reinf. Plast. Compos. 25 1001

[12] Huang X, Qi X, Boey F and Zhang H 2012 Chem. Soc. Rev. 41 666

[13] Jiang C H, Xu X B and Li Z M 2007 J. Macromol. Sci. B 4710

[14] Joon Choi W, Kim H J K, Han Yoon K, Hyeong Kwon O and Hwang C I K 2006 J. Appl. Polym. Sci. 1004875

[15] Khalaf E and Awad S 2017 JACS 3426

[16] Santos P and Pezzin S H 2003 J. Mater. Process. Technol. 143 517 